\title{
PERSPECTIVE Embracing Social Engagement in Academic Medicine: Ongoing Challenges and How to Move Forward
}

\author{
Bryn Falahee, MD, MPhil ${ }^{1,2,3}$ (1) and Vanessa Kerry, MD, MSc ${ }^{2,3,4}$ \\ 'Brigham and Women's Hospital, Boston, USA; ${ }^{2}$ Seed Global Health, Boston, USA; ${ }^{3}$ Harvard Medical School, Boston, USA; ${ }^{4}$ Massachusetts General \\ Hospital, Boston, USA.
}

Academic medical centers have historically been defined by scientific discovery for health advancement. However, the mounting challenges of modern medicine are fueled by the social, economic, and political determinants of health that predict vulnerability and accelerate poor outcomes. To surmount looming threats to health, the academic medical mindset must equally prioritize social engagement-work that directly addresses the systemic social causes of health and illness-alongside the traditional pedagogy of laboratory-based, translational, and clinical research. Considerable barriers still exist, rooted in historical priorities and significant funding structured to reward scientific achievements. Academic medicine has the agency to support elements of restructuring to help prioritize research, education, and training to more prominently include social engagement. Crucial steps to ensure the success of this process include prioritizing financial commitments to community-engaged scholarship and programmatic work and rigorous recognition of faculty who work on socially engaged scholarship within promotion schemes. The COVID pandemic presents an unprecedented opportunity for academic medicine to reflect on the breadth of the work we promote and encourage, work that reflects all the complex elements of health-those that can be documented in a lab notebook and those rooted in social systems and structures that we have neglected for too long.

$\mathrm{J}$ Gen Intern Med 37(5):1254-7

DOI: $10.1007 / \mathrm{s} 11606-021-07096-7$

(c) Society of General Internal Medicine 2021

$\mathrm{T}$ he COVID pandemic has confirmed the primacy of health for our wellbeing. As we emerge from this crisis, there is an opportunity for academic medical centers to harness new knowledge and define the critical — and broad-aspects of a complete health agenda moving forward. The disproportionate effects of the COVID pandemic on historically marginalized communities around the world clearly show how social, economic, demographic, and political context threaten the health and cost the lives of millions. ${ }^{1,2}$ Academic medical

Prior Presentation: This work has not been previously presented and is not under consideration elsewhere.

Received May 21, 2021

Accepted August 6, 2021

Published online September 9, 2021 centers have historically been defined by scientific discovery for health advancement and knowledge generation. Now, to truly surmount COVID and other looming threats to health, academic medicine must equally prioritize social engagement, alongside the traditional pedagogy of laboratory-based, translational, and clinical research.

\section{HISTORIC ROOTS OF SOCIAL ENGAGEMENT}

Socially engaged scholarship was initially discussed by Ernest Boyer in his seminal book Scholarship Reconsidered: Priorities of the Professoriate. ${ }^{3}$ Boyer described socially engaged scholarship as how knowledge can "be responsibly applied to consequential problems" and "helpful to individuals as well as institutions." 3 He noted that academic pursuits must help find and articulate solutions for pressing social, civic, economic, and moral problems. Compellingly, he argued that the "confidence of the nation's campuses themselves has grown during those times when academics were called upon to serve a larger purpose: to participate in the building of a more just society and to make the nation more civil and secure."4

In medicine, socially engaged scholarship can be defined as the implementation of practice, clinical service delivery, education, and research to directly address the systemic social causes of health and illness. Areas of applied scholarship are myriad and can include: social, service, or educational program development; direct programmatic work defined by implementation of a specific program or intervention; advocacy and policy change; direct service delivery to vulnerable or underserved populations; and advancement of social change through community partnerships. Research to evaluate the outcomes and effectiveness of applied interventions is also an important component of applied scholarship.

Such socially engaged scholarship is embedded in the history of modern medical academia. As Abraham Flexner wrote in his historic 1910 report that informed the structure of the modern academic medical institution, "disease has been found to depend largely on [an] unpropitious environment...a bad water supply, defective drainage, impure food, unfavorable occupational surroundings," and "the physician's function is fast becoming social and preventive, rather than individual and curative." ${ }^{5}$ He maintained that doctors have a duty "to promote social conditions that conduce to physical well-being" 6 
and centered the importance of the physician as a public servant in his arguments. ${ }^{6}$

Today, socially engaged scholarship remains central to modern medicine and the ability to advance health through scientific innovation, creative problem solving, and proactive social engagement. Therefore, it must inform how we train, deliver care, and dedicate research dollars and programmatic support.

Some argue that social engagement is not the job of academic medical institutions, that they should focus on more traditional research and science and leave social programming to public health, government systems, and community organizations. And yet, studies have demonstrated that $80-90 \%$ of a person's health is attributable to social determinants; in short, zip code is more important than genetic code for determining health. ${ }^{7-9}$ Social determinants of health mechanistically predict heart disease, cancer, and diabetes, ailments to which we dedicate dollars, time, and research studies. By investing equally in social engagement, academic medicine has the ability to intervene proactively and scientifically on crucial, modifiable steps in the biological causal pathway of disease.

\section{CURRENT BARRIERS}

Considerable barriers exist, embedded in historical priorities and funding structured to reward scientific achievements. A 2019 study performed by the National Institutes of Health (NIH) showed that NIH grant topics that include research at the community and population level tend to have lower award rates compared to more fundamental and mechanistic investigations; the choice of topic of investigation accounted for over $20 \%$ of the funding differences after controlling for multiple other variables, including an applicant's prior achievements. ${ }^{10}$ Additionally, in a culture where publications are promotion, direct service and programmatic work are often undervalued, treated as a derivative and not scholarship. ${ }^{3}$ This hierarchy influences not only funding allocation, but also academic advancement for faculty who work on applied or socially engaged pursuits. While these barriers are systemic, academic medicine has the agency to support elements of restructuring to help prioritize research, education, and training to better and more prominently include the social determinants of health.

\section{CRUCIAL NEXT STEPS}

Two crucial steps can be taken to ensure the success of this process. First, financial commitments to community-engaged scholarship and support for programmatic work must be included in academic institutional development priorities. Second, academic medicine must concretely and rigorously recognize faculty who work on socially engaged scholarship and programmatic work within promotion schemes; their work must be valued on par with laboratory-based research and translational contributions, and structured criteria for promotion need to be established.

\section{Funding Considerations}

As deans of medical schools and heads of academic hospital systems set fundraising objectives, thinking must expand to embrace social engagement as core to institutional priorities, and donor stewarding. The current political and social climate has helped pivot and galvanize donors to invest in socially oriented work, creating more opportunities for deans and development offices to prioritize funding for social engagement in robust and transformative ways. ${ }^{11,12}$

While advancements in social medicine initiatives often cost money upfront, rather than directly making it, there is tangible payout in the long-term savings and health benefits accrued. A comprehensive literature review of social service health investments between 2004 and 2014 found that greater than $80 \%$ of the studies evaluating income support programs, care coordination and community outreach interventions, and housing support programs, showed statistically significant, positive effects on health outcomes and health care spending. ${ }^{13}$ Recently, a randomized controlled trial from the University of Pennsylvania showed that their community health worker program resulted in an annual return on investment of $\$ 2.47$ for every dollar invested annually by Medicaid. The intervention arm resulted in a $38 \%$ reduction in cost and saved Medicaid \$1.4 million over 1 year. ${ }^{14}$ Academic medicine can make similar investments in the form of dedicated faculty research dollars and institutional fundraising priorities.

Internal reform at academic medical centers cannot occur in a vacuum. Priorities of national funding sources must help reinforce these changes. For example, the National Institute of Health $(\mathrm{NIH})$ funding streams contribute strongly to academic pursuits, fund academic clinicians at all levels, and are sources of indirect funds for institutions, which determine budgets and revenue. As NIH funds are allocated in part by legislative appropriations, a fundamental shift in the values of our government and lawmakers will need to occur. Advocacy from professional organizations and direct requests from academic institutions themselves could help move this forward. Beyond public sector funding, there is also an opportunity for large independent family foundations and other granting bodies to empower socially engaged scholarship through academic partnerships and investments, which would allow them to catalyze the unique knowledge generation and training opportunities present at academic medical centers. These funding shifts would powerfully sanction the importance of socially engaged medical work.

\section{Faculty Recognition}

For social engagement to be prioritized, faculty work on socially engaged scholarship must be valued on par with bench research and translational contributions. It must ultimately be written into systems of value, including promotion 
structures at the most highly financed and respected academic medical institutions. It cannot be seen as derivative or just "good work" secondary to the academic mission, but instead must be viewed as work critical to advancing health. An examination of promotion criteria from faculty handbooks from the top five medical schools for research, as ranked by US News and World Report, shows that promotion criteria typically fall into five key categories: publications and other scholarly work, funding awards, [home] institutional service contributions, teaching contributions, and awards or recognition. ${ }^{15-22}$ Across these top five medical schools, a relative paucity of metrics exists for quantifying community-engaged or applied work as part of the promotion criteria. ${ }^{15-22}$

In order for socially engaged work to be prioritized, promotion metrics need to be expanded to recognize a greater diversity of scholarly work including program implementation and subsequent evaluation and learning and diverse but impactful dissemination methods, including publishing in non-traditional spaces. Service contributions should be quantified not only as they benefit the institution but should also include those to the community outside the medical schools. Placing a greater diversity of faculty on promotion committees to represent those who work on socially engaged scholarship will help ensure the work is reviewed by faculty who understand its impact and scope. This shift may require flexibility, at least initially, in the academic rank of those serving on promotions committees, beyond just full professors.

\section{ONGOING EFFORTS}

Some medical schools are already leading the shift to include a wider variety of valuable faculty work in promotion criteria. For example, the Faculty 2020-2021 Handbook at the new Kaiser Permanente Bernard J. Tyson School of Medicine lists diverse parameters for faculty scholarship, including "reports for agencies or organizations, significant public communications for education or advocacy, inventions or patents, laws or regulations, institutional or professional policies." ${ }^{23}$ These parameters for scholarship are novel and highly relevant to work products that may arise from the scholarship of application or engagement. Their consideration in Kaiser's criteria represents a potential for changing the landscape of scholarship at medical schools. In addition, Kaiser specifically recognizes the scholarship of "application" in its faculty definitions of scholarship, right alongside teaching and traditional research. ${ }^{23}$ All medical institutions should consider similar updates to faculty promotion structures and criteria to support and reward faculty work on socially engaged projects. This work must be recognized not as derivative, but as work critical to moving the field of medicine forward.

\section{A TIMELY CONSIDERATION}

Today, medical practice is challenged by well-known and growing threats of non-communicable disease, sequelae of climate change, racism, and novel and staggering threats like COVID. Fueling these growing challenges are the social, economic, and political determinants of health that predict vulnerability and accelerate poor outcomes. The COVID pandemic presents an unprecedented opportunity for academic medicine to reflect on the breadth of the work we promote and encourage, work that reflects all the complex elements of health - those that can be documented in a lab notebook and those rooted in social systems and structures that we have neglected for too long. As trainees and attendings on the wards, we are taught to recognize and then respond to the pathophysiology of our patients. We need to embrace this same rigorous approach with the social pathology of poor health and suffering.

Corresponding Author: Bryn Falahee, MD, MPhil; Harvard Medical School, Boston, USA (e-mail: bryn_falahee@dfci.harvard.edu).

\section{Declarations:}

Contributors: No contributors exist outside the stated authors.

Conflict of Interest: The authors declare that they do not have a conflict of interest.

\section{REFERENCES}

1. Webb Hooper M, Nápoles AM, Pérez-Stable EJ. COVID-19 and Racial/ Ethnic Disparities. JAMA. 2020;323(24):2466.

2. Abrams EM, Szefler SJ. COVID-19 and the Impact of Social Determinants of Health. Lancet Respir Med 2020;8(7):659-661.

3. Boyer, Ernest L., Drew Moser, Todd C. Ream, and John M. Braxton. Scholarship Reconsidered: Priorities of the Professoriate. Expanded edition. San Francisco, CA: Jossey-Bass/A Wiley Brand, 2015.

4. Boyer, EL. The Scholarship of Engagement. $J$ Public Serv Outreach 1996;1(1):11-20.

5. Flexner A. Medical Education in the United States and Canada: A Report to the Carnegie Foundation for the Advancement of Teaching. Published 1910. http://archive.carnegiefoundation.org/publications/pdfs / elibrary/Carnegie_Flexner_Report.pdf.

6. Ludmerer KM. Commentary: Understanding the Flexner Report. Acad Med 2010;85(2):193-196. doi:https://doi.org/10.1097/ACM. Ob013e3181c8f1e7.

7. Hood CM, Gennuso KP, Swain GR, Catlin BB. County Health Rankings: Relationships Between Determinant Factors and Health Outcomes. Am J Prev Med 2016;50(2):129-135.

8. Braveman P, Gottlieb L. The Social Determinants of Health: It's Time to Consider the Causes of the Causes. Public Health Rep 2014;129(Suppl 2): 19-31.

9. RWJF Commission to Build a Healthier America. Beyond Health Care: New Directions to a Healthier America; April 1, 2009. Accessed October 9 , 2020. (https://www.rwjf.org/en/library/research/2009/04/beyondhealth-care.html.)

10. Hoppe TA, Litovitz A, Willis KA, et al. Topic Choice Contributes to the Lower Rate of NIH Awards to African-American/Black Scientists. Sci Adv. 2019;5(10):eaaw7238.

11. Levine RE. Power in Global Health Agenda-setting: The Role of Private Funding. Int J Health Policy Manag 2015;4(5):315-317.

12. Prina LL. Funding to Improve Social Determinants of Health. Health Aff 2019;38(9): 1589-1590.

13. Taylor LA, Tan AX, Coyle CE, et al. Leveraging the Social Determinants of Health: What Works? PLoS One. 2016;11(8).

14. Kangovi S, Mitra N, Grande D, Long JA, Asch DA. Evidence-Based Community Health Worker Program Addresses Unmet Social Needs and Generates Positive Return on Investment. Health Aff 2020;39(2):207-213.

15. Harvard Medical School and Harvard School of Dental Medicine. Governance, Appointment, and Promotion Handbook. December 2020. 
16. University of Pennsylvania, Perelman School of Medicine. Academic Clinician Appointment, Reappointment and Promotion Criteria. January $24,2019$.

17. University of Pennsylvania. Faculty Handbook, II. Faculty Policies and Procedures. Accessed February 10, 2021. https://catalog.upenn.edu/ faculty-handbook/ii/.

18. Johns Hopkins University School of Medicine. Policies and Guidelines Governing Appointments, Promotions, and Professional Activities of the Full-time Faculty of The Johns Hopkins University School of Medicine. October 2018.

19. Stanford University School of Medicine. Academic Affairs Handbook. School of Medicine Faculty Handbook. Accessed February 10, 2021. http://med.stanford.edu/academicaffairshandbook.html.

20. NYU School of Medicine. Revision to the Policies and Procedures for Appointment, Promotion and Tenure at the School of Medicine. November 22,2016
21. NYU Grossman School of Medicine. Overview of Career Development Expectations and Criteria for Promotion on the Non-Tenure Eligible Tracks at NYU Grossman School of Medicine. Revised January 16, 2021.

22. University of Pennsylvania, Perelman School of Medicine. COAP Guidelines. Revised March 2016

23. Kaiser Permanente Bernard J. Tyson School of Medicine Faculty Handbook, Version 1.0. Published online June 2020. https:// medschool.kp.org/content/dam/internet/kp/som/homepage/faculty/ KPSOM\%20Faculty\%20Handbook.pdf

Publisher's Note: Springer Nature remains neutral with regard to jurisdictional claims in published maps and institutional affiliations. 